\title{
A APREENSÃO SENSÍVEL DA NATUREZA EM GOETHE E HUMBOLDT
}

\section{THE SENSITIVE APPREHENSION OF NATURE IN GOETHE AND HUMBOLDT}

\author{
Esdras Arraes
}

\section{Resumo:}

O texto busca interpretar as noções de natureza e paisagem em certas obras de Johann Wolfgang von Goethe e Alexandre von Humboldt. Para ambos, enquanto que a natureza seria a totalidade dos fenômenos naturais, a paisagem seria um fragmento dessa totalidade enquadrada pela experiência do olhar constantemente treinado. Assim, a paisagem, tanto para Goethe como para Humboldt, é formulada pelo desejo de apresenta-la segundo a dimensão estética, isto é, seria necessário sensibilidade e imaginação para perceber a natureza em sua completude. No início do ensaio mostra-se a noção goetheana de natureza e paisagem lançando luz sobre alguns de seus romances e doutrinas científicas, tais como Os sofrimentos do jovem Werther, Novela ou história de uma caçada e Metamorfose das Plantas. Em seguida, apresenta-se o entendimento humboldtiano sobre ambas as categorias assimiladas segundo poesia e ciência. Finalmente, analisa-se algumas afinidades e diferenças conceituais que há entre o poeta e o naturalista prussiano.

Palavras-chaves: Johann Wolfgang von Goethe. Alexandre von Humboldt. Natureza. Paisagem. Pintura. Poesia

\section{ABSTRACT:}

The paper seeks to interpret the concepts of nature and landscape in some Johann Wolfgang von Goethe and Alexander von Humboldt works. For both, while nature is comprehended as a totality of natural phenomena, landscape would be a fragment of that totality framed by experience of the eye. However, Goethe and Humboldt view of nature is shaped by the desire to present it as an aesthetic dimension, is that to say, it would be necessary sensibility and imagination to perceive nature in its completeness. First, it presents the goethean view of nature and landscape throwing some light in his mainly novels and scientific treaties, such as The sorrows of Young Werther, Novel or history of hunt and The metamorphosis of plants. Next, it shows how Humboldt understood both categories by means of poetry and science. In the end, it intends to analyze some affinities and differences between the poet and Prussian naturalist.

Keywords: Johann Wolfgang von Goethe. Alexandre von Humboldt. Landscape. Nature. Painting. Poetry 
"Já há muito tempo não consigo deixar de atribuir as alterações que se deixam perceber na atmosfera em grande parte a um efeito interior, silencioso e secreto dessas mesmas montanhas".

Goethe em Innsbruck, 1786.

\section{INTRODUÇÃO: NATUREZA - O JARDIM DO MUNDO E}

O COSMOS

Este ensaio faz parte de uma pesquisa de pós-doutorado em andamento na Faculdade de Filosofia, Letras e Ciências Humanas da Universidade de São Paulo (FFLCH-USP) que explora a natureza e a paisagem, e suas relações com a Estética, como princípio heurístico. Busca-se, na esteira do pensamento de Raffaele Milan (2008, p. 47), compreender o significado da paisagem como categoria do pensamento tomada desde a perspectiva da fruição da idealização e do manifestar da natureza em alguns escritos do poeta Johann Wolfgang von Goethe e do naturalista prussiano Alexander von Humboldt. A abordagem que se segue não tem a pretensão de dar conta da completude do entendimento das categorias em termos filosóficos e historiográficos. Por isso, não gostaria de esgotar aqui a problematização da noção de natureza e de paisagem, senão recorrer a um limitado número de obras que põem luz sobre o tema abordando suas implicações espirituais, sensíveis e no campo das ideias.

A compreensão da natureza, tanto em Goethe como em Humboldt, aparece como experiência estética e científica, quer dizer, a natureza não seria um simples objeto das ciências naturais centradas em sistematizá-la em especificações racionais, como sugerem os modelos de classificação botânica de Carl Lineu ou as imagens da natureza apresentadas como sistema mecânico na Enciclopédia de D'Alembert. Goethe considera a nomenclatura "sistema natural" contraditória e insuficiente para descrever os fenômenos da natureza. A natureza não tem sistema,"tem simplesmente, é vida e ritmo, nasce de um centro desconhecido e dirige-se para um limite reconhecível. Por isso a observação da natureza é infinita" (GOETHE, 2012, p. 2). Ou, como diria Rousse- au, "tudo na Terra está em fluxo contínuo e não permite a nada assumir uma forma constante" (ROUSSEAU, 2017, p. 116). Poeticamente, a natureza investigada por Goethe assume a forma do efeito secreto das montanhas contemplado na atmosfera, isto é, a natureza é, no interior de sua significação, essencialmente polarizada. Ações opostas, como o velado pulsar orográfico e o caminhar ligeiro das nuvens criam a eternidade da natureza.

Por seu turno, Humboldt relembra, no segundo volume de Cosmos, que o estudo da natureza e de seus quadros (paisagens) envolveria uma componente sensível pela qual a liberdade de apreciar paisagens confere ao rigor empírico sua completude. Ele exprime, ainda, os "receios de perder a livre fruição da natureza sob a influência de uma contemplação intelectual ou de um conhecimento científico" (HUMBOLDT, 1852, p. 15). Isso equivale a pensar, segundo Juan Antonio Ortega y Medina (2000, p. 92), que o cientificismo de Humboldt, cujas raízes não podem ser senão racionais e ilustradas, se orienta em direção a uma febril e multiforme atividade empírica, mas que, não obstante, ele a acomoda ao sentimento, à poesia e inclusive à fé deísta como se pode observar em suas obras, sobretudo, Quadros da natureza e Cosmos.

Os escritos de Goethe e Humboldt celebram a "natureza" e a "paisagem" como duas entidades vivas, mas, de certa maneira, distintas. Enquanto que a natureza envolve a totalidade dos fenômenos, ou o cosmos na reflexão humboldtiana, a paisagem seria um "quadro da natureza", uma unidade dessa totalidade abarcada pela experiência do olhar constantemente treinado. 0 quadro da natureza subsome a forma, uma unidade orgânica composta de diferentes partes que se relacionam entre si por meio de processos simultâneos. Essa forma, ou fisionomia na interpretação do naturalista, é decorativa, e conecta emoção, arte e natureza: "o conhecimento das montanhas e das pedras que delas se extraem resultaram em grande progresso no que diz respeito à arte" (GOETHE, 2017b, p. 97)

A natureza como cosmos conotaria ordem e decoração. Humboldt fala do "significado da palavra cosmos designar ordem do mundo e ornamento da ordem universal" (HUMBOLDT, 1852, p. 31). A 
paisagem, por seu turno, seria uma fração do cosmos que se torna esteticamente presente no olhar de um contemplador sensível, o qual, porventura, transmite-a em formas dizíveis e/ou visíveis.

\section{O MUNDO DO OLHO: NATUREZA E PAISAGEM EM Goethe}

Johann Wolfgang von Goethe (1749-1832) orbitou no universo da ciência, em especial a partir de 1780, quando inicia seus estudos sobre mineralogia. Antes, quando vinculado ao movimento Sturm und Drang ${ }^{1}$ (Tempestade e Ímpeto), a literatura e as artes plásticas colocam-se como centro de sua preocupação. Nesse momento, o poeta escreve, dentre outros trabalhos, o ensaio intitulado Sobre a arquitetura alemã (GOETHE, [1772] 2005) e o romance Os sofrimentos do jovem Werther ([1774] 2009), o qual causou fortes reações na sociedade coeva em decorrência da nociva paixão do protagonista. Em Sobre a arquitetura alemã, Goethe se empenha em demonstrar os efeitos suscitados pela catedral de Estrasburgo ao olhar atento às formas concebidas pelo mestre de obras Erwin von Steinbach. A assimetria característica da volumetria do templo não denigre o equilíbrio do projeto arquitetônico, mas aguça os vínculos entre a catedral (totalidade) vivificada pelos inumeráveis motivos decorativos (partes). Assim, o efeito do todo sobre o espectador seria parcial se suas partes não fosse devidamente apreciadas.

Já o romance epistolar Os sofrimentos do jovem Werther dividese em duas partes. A primeira introduz como temas o amor e a co-respondência do protagonista com a natureza. As descrições do mundo que envolvem Werther traduzem-se em paisagens que comunicam a sintonia do seu espírito com a natureza. É in-

1 Georg Lukács afirma que o Sturm und Drang havia sido a sublevação do "sentimento" e do "instinto vital" contra a tirania do entendimento, representando a luta contra Iluminismo. Tratou-se de uma disputa de jovens espíritos (Hamann, Herder, Goethe e Lenz) cujos temas básicos eram a incompatibilidade entre o indivíduo e a sociedade, a ênfase no gênio criador que se afirma livre das preceptivas artísticas, o sentimentalismo e a linguagem violenta que busca o exercício da crítica ferrenha. Recomenda-se a leitura dos textos de Georg Lukács (1968) e de Marco Aurélio Werle (2000) para o melhor aprofundamento das questões literárias e filosóficas do Sturm und Drang. teressante chamar a atenção, conforme as reflexões de Marco Aurélio Werle (2017), que a ideia de subjetividade não significa um recuo interior para a formalidade dos sentimentos; seria, por outro lado, a expressão da afinidade do eu imerso na unidade da natureza.

A co-respondência entre Werther e a natureza anuncia-se na carta que abre a narrativa da obra. Nela, há a resoluta decisão de sepultar os constrangimentos do passado em seu tempo devido, apreciando a vida e o manifestar dos eventos do presente. Inclusive a cidade, com seus vícios e mundanidade, espetáculos e técnicas, é abandonada por Werther que vai buscar refúgio nas regiões campestres, inocentes e simples, propícias a apaziguar o ímpeto do espírito juvenil. A afetuosidade dessa paisagem pastoral comunga-se com a dócil imagem de crianças que o observam na praça da pequena povoação de Wahlheim. A cena o induziu a desenhar uma imagem, cujo propósito pictórico fortaleceu sua ligação com o lugar:

A primeira vez, numa tarde linda, quando o acaso me levou para debaixo daquelas tílias, achei o lugar bem solitário. Estavam todos no campo; apenas um menino de quatro anos estava sentado no chão, abraçando uma outra criança de uns seis meses, sentada entre suas pernas como se estivesse numa poltrona...Deu-me prazer vê-los ali; sentei-me num arado defronte e avidamente comecei a desenhar aquela postura fraternal. Acrescentei a cerca mais próxima, a porta do celeiro e algumas rodas quebradas...sem colocar nada de meu. Isso fortaleceu o meu propósito de manter-me doravante unicamente ligado com a natureza. (GOETHE, [1774] 2009, p. 24)

Werther recorre à solidão, a essa condição divina contemplativa de venerar e pensar sobre a natureza enquanto paisagem, enquanto mediação estética da harmonia proporcionada pelo todo. É na solidão que a paisagem se transfigura em idílio, unificando a existência e o existente numa unidade afim: "estou me sentindo muito bem aqui. Nessas terras paradisíacas, a solidão é um bál- 
samo valioso para meu coração, tão fortemente aquecido pelo fervor juvenil" (GOETHE, [1774] 2009, p. 14). O único livro que o acompanha nesse ato de reconciliação com a paisagem é um "Homero". A leitura vem a calhar com seu renovado estado de ânimo (stimmung), pois a evocação dos clássicos assume a forma de refrigério incorporado à apreensão sensível da natureza.

O silêncio, que para o nosso protagonista representava o estado elevado do espírito, divino portanto, também aparece no opús culo Novela ou a história de uma caçada. Depois de testemunhar os efeitos danosos produzidos por um incêndio na feira de um pequeno povoado, artistas circenses (uma mulher, um homem e uma criança) passaram a entoar uma elegia em honra à morte de um dócil tigre e à fuga do leão da companhia. Os ouvintes apreciaram o lamento, pelo qual pairava um total silêncio, "era como se todos os perigos tivessem caídos no esquecimento: lá embaixo o incêndio, lá em cima, o leão a descansar" (GOETHE, s.d., p. 63).

A leitura de Goethe a respeito do silêncio e da solidão, tomados a partir da observação da paisagem, que diz sobre a nossa vivência na Terra, aproxima-se da exposição rousseauniana narrada em Os devaneios de um caminhante solitário (2017). Logo na primeira caminhada, Rousseau relata sua estranheza diante do mundo devido aos objetos penosos que lhes causam revolta e aflição. Para tanto, ele recorre, assim como Werther, às distrações do caminhar ocupado em contemplar a paisagem, inspecionar os objetos da natureza e perscrutar as modificações da alma e seus desencadeamentos (ROSSEAU, 2017, p. 14).

Goethe manteve certos princípios da fase do Sturm und Drang em suas reflexões ulteriores, como as polaridades totalidade e unidade ou subjetividade e objetividade. A polaridade, que se torna uma unidade, aparece em seus estudos sobre a natureza levados a cabo durante sua viagem à Itália (1786-1788), mas sobretudo em Metamorfose das plantas ([1790] 1993) e Doutrina das Cores ([1810] 2013).

Em Poesia e verdade, Goethe revela o olhar como o sentido em que ele melhor apreendia o significado do mundo envolvente. Se recuarmos no tempo, notaremos que o observar se fez presente desde sua juventude. No momento da festividade de coroação do rei José II, em 1763, o futuro poeta usou parte do seu dia observando tudo "que se oferecia publicamente" às vistas, criando impressões vivas daquele agitado e teatral evento (GOETHE, 2017a, p. 270). Ao explicar a Schiller o propósito da redação de Doutrina das Cores, Goethe acentua o primado da contemplação da natureza como experiência interativa entre a objetividade das formas vistas e a subjetividade das emoções. Na realidade, dizia o autor de Fausto, descortinava-se "o mundo do olho" que se consome por formas e cores (CORRESPONDANCE, 1845, p. 195). Na crítica feita ao manual As belas artes de Sulzer sustenta-se a hipótese de que a ideia formulada no campo perceptual da visão converte-se em fundamento de autêntico conhecimento (GOETHE, [1772] 2005, p. 54). Por isso, Goethe aconselhou ao jovem Eckermann, antes de dar início à elaboração de poemas, a prestar atenção aos objetos, às formas da paisagem, compreendendo-as em sua individualidade como parte essencial da vida da arte e imprescindíveis à educação do artista (ECKERMANN, 2016, p. 158).

Além disso, Goethe percebeu o primado do mirar na elaboração de sua "heurística viva", uma metodologia interconectada entre o dizível e o visível, pela qual ambas as categorias se unificam quando o assunto seria, dentre alguns aspectos, a leitura de objetos: "no momento...em que se tem um contato seguro por meio do olhar, só então é que se pode ler e ouvir, pois a isso se associa a impressão vívida. Só então se torna possível pensar e julgar" (GOETHE, 2017b, p. 181). Dessa maneira, o movimento do pensamento de Goethe é de "inspiração" e "expiração", isto é, as reflexões sobre os objetos davam-se a partir do entendimento pormenorizado de suas qualidades exteriores, daí consegue-se reverberá-las ao espírito; enquanto que este nos leva suavemente à subjetividade, aquele nos orienta para fora de nós mesmo (ARRAES, 2018, p. 5). De acordo com Maria Filomena Molder (1995, p. 65), o projeto heurístico goethiano refere-se à aceitação das afinidades e benevolências para com as diferenças movidas à totalidade, ao agrupamento da diversidade que se equacionam numa unidade a partir de procedimentos polarizados: sístole/diástole, análise/síntese, luz/sombra, e assim por diante. 
A paisagem revela-se nos escritos do autor de Werther no universo da pintura, como um "quadro da natureza", uma forma composta de objetos (naturais, antrópicos) e cores concordantes destinada à contemplação desinteressada sob o signo do frui em vez do uti (ARRAES, 2017, p. 43). A ideia de "quadro da natureza" já estava sedimentada e difundida no início do Setecentos em relatos de viagem ao redor da Europa. No entanto, será com Alexander von Humboldt (1852), com a publicação de sua monumental obra Cosmos, que o conceito de quadro da natureza abrigará embasamento científico, em outros termos, a paisagem circunscreveria, dentre alguns aspectos, o estudo experimental da natureza.

O quadro da natureza envolve o enquadramento do olhar, uma janela objetiva ou virtual que cinde o mundo articulando-o em cenas narradas/pintadas em vivo colorido. $O$ aparecimento da "janela" seria a condição sine qua non do surgir da paisagem e o instrumento paisagístico por excelência (CAUQUELIN, 2007, p. 137). Por todo o itinerário de Goethe em solo alemão e na Itália é frequente a composição de paisagens nessas "janelas": "o pequeno povoado conhecido como Stadtamhof ajuda a compor um belo quadro" (GOETHE, 2017b, p. 23). Entretanto, o poeta reconhecia seus limites: "é preciso antes acostumar meus olhos aos quadros" (GOETHE, 2017b, p. 24).O pouco treino o levaria ao intuito da estadia na "Arcádia": perscrutar os objetos da antiguidade e modernos, direcionar seu espírito em direção aos vapores e cores das paisagens da Itália, exercitar seu olhar sensível ao mundo exterior, o qual, de fato, já estava habituado a ver o mundo à maneira dos pintores: "para onde quer que eu olhasse, enxergava um quadro...tudo que me chamava à atenção, tudo $o$ que me encantava eu queria logo capturar" (GOETHE, 2017a, p. 270). Na realidade, a visível o auxiliou na elaboração do dizíve condizendo-se um com o outro: "e do mesmo modo como era comum produzirem gravuras em cobre para um poema, passei a escrever poemas a partir de gravuras e desenhos...assim acabe me acostumando a observar o modo com as artes se relacionavam uma com as outras" (GOETHE, 2017a, p. 378).

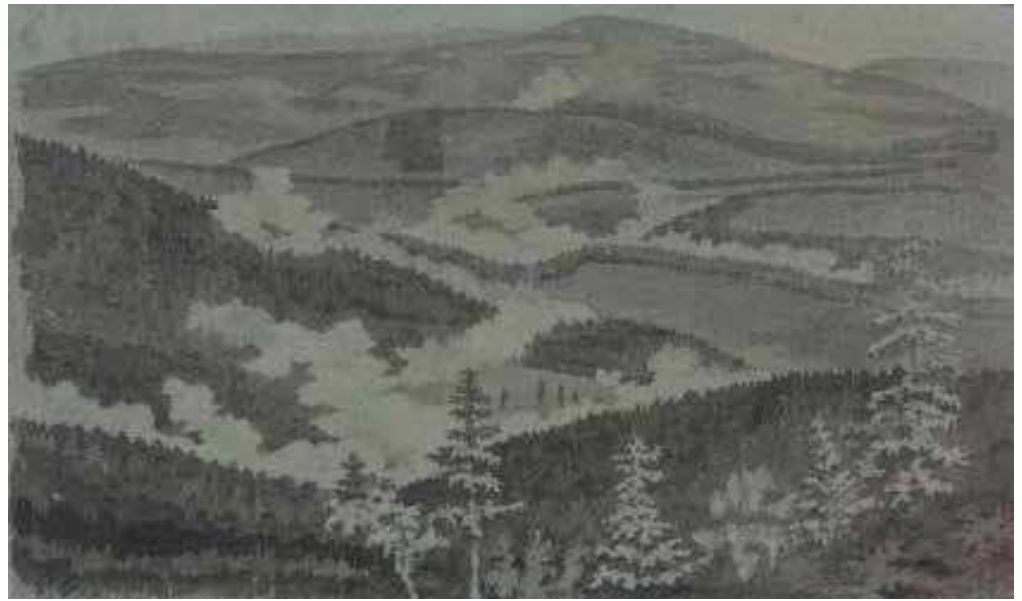

Figura 1 - GOETHE, J. W. Vale Brumoso em Illmenau.

Fonte: Javier Arnaldo et al, 2008, p. 130

Os desenhos do jovem poeta mostram claramente sua predileção pela representação da natureza e dos seus fenômenos correlatos. Nota-se esse gosto nos estudos de árvores e nuvens, nas visões noturnas tomadas da floresta de Turingia, no vale brumoso em Ilmenau (figura 1) e no belo desenho do jardim de sua casa em Weimar ${ }^{2}$. Goethe, no transcurso de sua viagem à Itália, elogia a veduta, as vistas tomadas do território esboçadas no papel, cujo valor documental e afetivo subjaz a noção de paisagem antes referida (BESSE, 2006, p. 72). Nos textos compilados em $A$ viagem à Itália arte e natureza são afins e se complementam, embasando o desígnio classicista de Goethe centrado no estudo das ciências naturais e das artes sob o imperativo da sensibilidade do olhar que sempre é dinâmico e transformador (GALÉ, 2009, p. 29).

Ainda na Itália, Goethe acentuou seu interesse pela observação dos fenômenos naturais e, sobretudo, à apreciação da natureza em pintura de paisagem. Em Nápoles, ele se encontrou com Jacob Philipp Hackert, pintor do rei Fernando IV e um dos prin-

2 Os desenhos de Goethe encontram-se compilados em Javier Arnaldo et al (2008). 
cipais paisagistas da época. Goethe reconhecia que os desenhos feitos por Hackert, elaborados segundo a tradição figurativa do pintor francês Claude Lorrain, eram os modelos de representação da modernidade. A pintura de paisagem aparece como objeto dos discursos das trocas epistolares entre o poeta e o pintor do rei Fernando IV. Nelas, Goethe exprime que a paisagem "real" e sua transmutação para a imagem evocam uma natureza apreendida pelo constante treino do olhar. Nesse aspecto, o autor de Fausto promove uma certa cultura do olhar adquirida após suas experiências, ou melhor, seu "renascimento" em terras italianas. Numa das cartas, Hackert escreve para seu amigo opinando que o artista deve ser, antes de tudo, um bom observador do mundo envolvente, dedicando tempo para desenhar e conhecer os objetos (HACKERT; GOETHE, 2002). Com efeito, não bastava pintar uma tília, senão aprofundar a relação entre artista e árvore para então transmitir, em vivas cores e formas, a essência da natureza, a decoração do mundo e a ordem do cosmos.

No jardim botânico da Universidade de Pádua, Goethe esboçou a ideia de Urpflanze, ou a "planta original", como o princípio formal que nortearia seus estudos de botânica (GOETHE, 2017, p. 71). A Urpflanze - assim como o Urphänomen (fenômeno original) utilizado para aludir à causa ideal de toda manifestação da natureza - pertence, de certo modo, aos fundamentos da teoria goetheana de visualidade, pois estimula ver o geral no particular e obter o geral no tratamento do particular. A expressão característica que subjaz a planta sempre é, para Goethe, o resultado coordenado da "lei interna da natureza, no qual a planta fo constituída" e a "lei do meio ambiente, pelo qual a planta fo modificada" (MILLER, 2009, p. 21). Nesse sentido, o desenvolvimento de formas orgânicas prossegue tanto do interior para o exterior como de fora para dentro. Os parágrafos 24 e 25 de $A$ metamorfose ([1790] 1993, p. 19) mencionam como a estrutura da folha pode ser afetada pela umidade ou secura do lugar, e como a nutrição excessiva pode retardar a floração (\$30). Como veremos a seguir, a metodologia goetheana de estudo botânico influenciou positivamente o pensamento humboldtiano, em especial no livro Essay on the Geography of plants ([1807] 2009), cuja versão alemã foi dedicada ao seu amigo poeta.

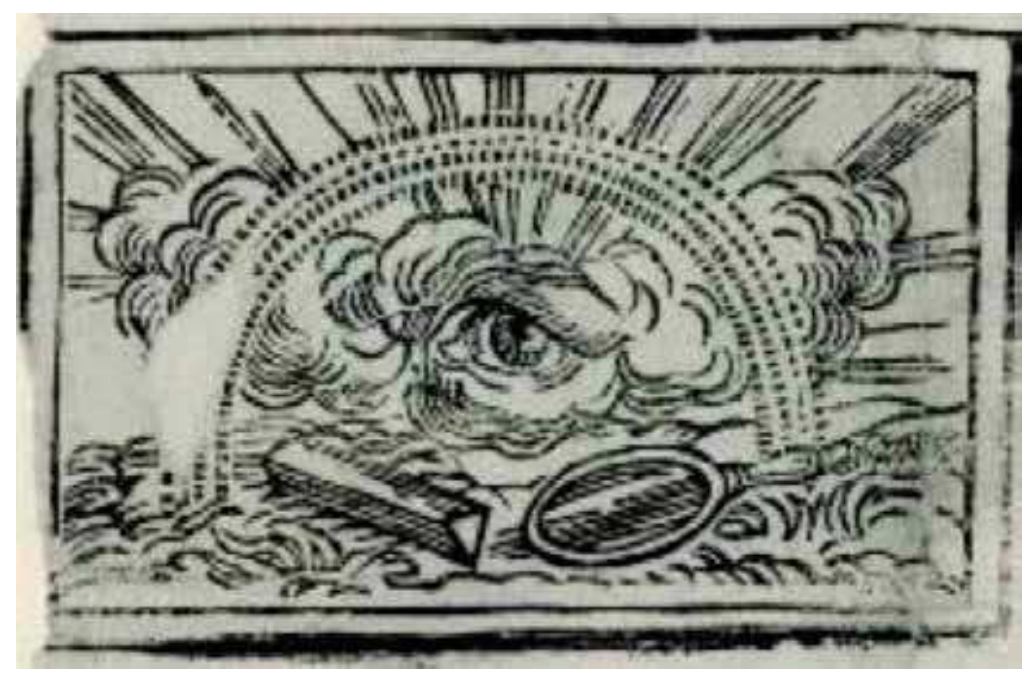

Figura 2 - Vinheta do Olho.

Fonte: Javier Arnaldo et al, 2008, p. 24

Num desenho que Goethe fez de seu olho envolvido por um arco-íris (figura 2), ilustra-se perfeitamente o panegírico à visualidade. Além de nuvens e raios solares emanados do olho, um prisma e uma lupa, posicionados abaixo do órgão da visão, enfatizam, alegoricamente, a prevalência da mirada e das faculdades do espírito humano sobre o empirismo das teorias científicas. 0 "mundo do olho", traduzido no olhar estetizante em consonância com aquele dos fenômenos objetivos, é o assunto eminente em Doutrina das cores e nos desenhos de paisagens elaborados no transcurso da viagem à Itália. A teoria das cores goetheana refere-se à ativa conformidade entre o espírito e a visualidade. Em Doutrina das cores, Goethe explora polaridades (luz e sombra) no intuito de interpretar a gênese das cores à base do claro e escuro, opondo-se ao tratado de Newton que as considera como fragmentos da luz branca facilmente calculáveis em fórmulas matemáticas. A luz, Urphänomen, se desdobra em sombras e cores, 
uma deflagração que repercute sobre os corpos e os faz ressoar como paisagem ao olhar do espectador. Por isso, a paisagem torna-se, sob esse aspecto cromático, o destino e a vocação da luz e a revelação da cor (BESSE, 2006, p. 55).

Olho e luz são afins na formação das cores (GOETHE, [1810] 1993, p. 45). Isso sugere, de acordo com o comentário de Pedro Galé (2009), que há "uma ligação produtiva do observador em relação aos objetos, existe no sujeito um ato criador ativo, que se desenvolve justamente com o contemplar, que fixa os mais estranhos e opostos fenômenos combinando seus elementos no intento de compreendê-los" (GALÉ, 2009, p. 70). O que de fato Goethe busca explicar com sua teoria das cores é a natureza revelada através do olho sensível. Uma natureza reconhecida como unidade que está em harmonia com suas partes num processo vivo e infinito, essa é a ideia de natureza que vai se potencializar, ou, no mínimo, terá sua aplicabilidade nos estudos de Alexander von Humboldt.

\section{Os quadros da natureza de Alexander von HUMBOLDT}

Joaquim Ritter (2013), em texto já considerado clássico por arquitetos e filósofos da paisagem, argumenta a expressividade dos escritos de Humboldt de converter a natureza apreensível segundo dispositivos poéticos e pictóricos, na sua relação com o olho sensível de transformá-la esteticamente em paisagem. Com efeito, ao comentar sobre as estepes em Quadros da natureza ([1808] 1876) (Ansichten der Natur ou Tableaux de la Nature), Humboldt imprime emoção na sua descrição de planícies que suscitam a imagem do infinito: "quando a extremidade das planícies se ilumina com o nascimento rápido de astros brilhantes, ou ao refletir sua trêmula luz sobre as camadas inferiores dos vapores ondulantes, acredita-se que tenha diante dos seus olhos um imenso oceano. Assim, as estepes também enchem a alma com o sentimento de infinito" (HUMBOLDT, [1808] 1876, p. 2).

O empenho de compreender a natureza sensivelmente aparece, sobretudo, em Cosmos, sua obra mais importante que define a natureza como "uma unidade na diversidade dos fe- nômenos" (HUMBOLDT, 1852, p. 9). Nessa obra, a explicação da totalidade natural surge sob a forma de dois aspectos complementares: observar os fenômenos em sua realidade objetiva e refletir como a humanidade projeta seus sentimentos sobre a natureza. Se as ciências fundadas em observação rigorosa transmitem leis dando a conhecer os fenômenos do universo, o espetáculo da natureza ficaria incompleto caso não fossem considerados o pensamento e a imaginação dispostos em impressões poéticas (HUMBOLDT, 1852, p. 6). Ele recorda, ainda, que a destinação do homem seria "captar o espírito da natureza oculto por detrás das manifestações", a fim de abarcar a natureza como um todo, para então "submeter simultaneamente a matéria bruta da intuição empírica através das ideias" (HUMBOLDT, 1852, p. 15)

Como em Goethe, a paisagem para Humboldt surge a partir da apreciação poética e figurativa de um quadro da natureza. No segundo tomo de Cosmos, o naturalista prussiano comenta três maneiras de propagar o estudo da natureza pelas quais a imaginação e a sensibilidade criadora do homem manifestam-se: a primeira seria a poesia ou as descrições animadas de cenas da natureza; a pintura de paisagem vem a ser a segunda forma, aliás ela mesma uma modalidade de poesia; e, por último, os jardins, lócus simultâneo de contemplação e investigação dos fenômenos naturais, particularmente os botânicos (HUMBOLDT, 1852, p. 9). Ao definir esses três dispositivos, Humboldt pretendia expor de modo particular como o mundo exterior interferiu diversamente sobre o pensamento e imaginação em diferentes épocas e povos. Por meio da literatura consegue-se perceber como o espírito humano qualifica a paisagem. Assim, dos gregos a Goethe, a poesia explicou em rimas as leis que movem a natureza. O elogio à produção bibliográfica de Goethe é flagrante no momento em que Humboldt menciona $O$ sofrimento do jovem Werther, Viagem à Itália e Metamorfose das plantas, obras cujo teor poético respira sentimentos profundos pela natureza e paisagem (HUMBOLDT, 1852, p. 31)

Compreender de que maneira Humboldt utilizou a pintura de paisagem, como instrumento de análise científica e artística, terá 
consequências no desenvolvimento do gênero nas Américas como um todo (MATTOS, 2004, p. 154). A pintura de paisagem devota à natureza uma espécie de discurso codificado em imagens desenhadas conforme se vê in natura os objetos orgânicos: "os esforços dos artistas serão mais felizes...se eles pintaram, ao ar livre, as copas das árvores carregadas de flores e frutos, árvores cheias de orquídeas, algumas rochas, uma pequena escarpa, alguma parte no fim da selva..." (HUMBOLDT, 1852, p. 36). Mas a vocação da pintura seria apresentar a rica variedade das formas exteriores, inclusive podendo unir o visível ao invisível. Para elucidar essa dualidade, Humboldt prossegue: "a pintura de paisagem possibilita a contemplação da fisionomia das plantas nos diferentes espaços da terra, convidando-nos de um modo instrutivo e agradável a entrar em acordo com a livre natureza" (HUMBOLDT, 1852, p. 36). Nesse aspecto, cada região do globo terrestre, seja a floresta, as Cordilheiras dos Andes, o deserto, o "céu da Grécia" ou os Alpes suíços, caracteriza-se por uma fisionomia individual e diversificada das demais. Imaginar a paisagem em termos fisionômicos significa atribuir-Ihe uma carga ontológica própria, isto é, se o quadro da natureza possui uma fisionomia, é preciso entende-la como uma unidade expressiva vivificada por uma realidade exterior (visível) conjugada com um "espírito interno" (invisível) do qual se pode extrair o sentido da livre natureza (BESSE, 2006, p. 72).

No entanto, existe um limite na pintura de paisagem: a apreciação da natureza é incompleta na medida em que a tela afeta menos o espírito do que a contemplação imediata de plantas agrupadas em jardins (HUMBOLDT, 1852, p. 41). O jardim de princípios do século XIX converte-se no lugar onde ciência e arte mesclam-se com objetivos estéticos e pedagógicos. Propósitos que não se circunscrevem unicamente na disseminação de estudos científicos; ao contrário, a jardinagem incluía a arte de criar paisagens. Criar porque todo jardim origina-se de um projeto que reúne aspectos empíricos e sensíveis, como a técnica da perspectiva, a simetria, a modulação, o jogo da luz e da sombra, a solidão, o repouso, a variedade das plantas e as cores.

Alguns comentadores sugerem que o estudo da vegetação, em vez das especificidades botânicas das plantas, revelou ser outra novidade do empirismo humboldtiano ${ }^{3}$. Em 1802, durante suas expedições na América espanhola, Humboldt, na companhia de Aimé Bonpland, traçou suas primeiras reflexões acerca da interferência do mundo natural e da humanidade na formação de grandes massas vegetativas. O livro - Essay on the Geography of plants-finalizado em 1807, é a peça-chave de um trabalho dedicado a compreender a vegetação, estética e cientificamente, como a totalidade da conjunção dos fenômenos naturais e humanos: "eu deveria chamar a atenção dos físicos aos fenômenos exibidos pela natureza nas regiões que tenho visitado. É seu todo que tenho considerado neste ensaio" (HUMBOLDT, ([1807] 2009), p. 61). O autor de Cosmos direcionou seu propósito heurístico à vegetação (totalidade), tendo em vista que a compreensão da natureza seria parcial se pensada exclusivamente no particular (plantas), pois nada pode ser considerado isoladamente. Outra vez, nota-se o diálogo entre as reflexões do naturalista com o pensamento goetheano, como se verificou no ensaio dedicado à catedral de Estrasburgo.

Para Humboldt, os resultados dos ensaios científicos devem ser esteticamente satisfatórios. Dessa maneira, a vegetação expressaria, dentre alguns aspectos, as condições materiais e espirituais de uma região. Mas é a sensibilidade humana que imprime o verdadeiro caráter da vegetação: "O homem que é sensível às belezas da natureza...terá prazer em examinar as variadas sensações que a vegetação produz na alma ao contemplá-la" (HUMBOLDT, ([1807] 2009), p. 73). Sob esse ponto de vista, deve-se chamar a atenção do Tableaux physique des Andes et pays voisins (HUMBOLDT, ([1807] 2009), p. 76-143). O tableaux é uma representação de um perfil dos Andes na altura do Chimborazo com o Coto-Paxi (figuras 3 e 4). Ali, estão mapeadas a localidade onde determinadas espécies de plantas crescem, a altitude favorável para o surgimento de diferentes vegetações, quais espécies de animais conseguem viver em altas latitudes e os métodos de dimensionar os parâmetros orográficos. Trata-se do emblema de uma paisagem percebida segundo a empiria e a imaginação: "eu penso que o meu quadro é capaz de sugerir analogias inesperadas aos que estudarão (os Andes) com mais detalhe, também 3 A esse propósito, ver o artigo de Anne Buttimer (2001, p. 105-120). 
seria capaz de aguçar a imaginação e proporcionar prazer aos que vêm apreciar a benéfica e majestosa natureza" (HUMBOLDT, ([1807] 2009), p. 79). Humboldt, nessa passagem, explicita a sintonia entre razão e espírito, mostrando como a imaginação torna-se uma categoria fundamental à ciência do seu tempo.

A paisagem narrada no Essay on the Geography of plants combina variáveis da natureza (vegetação, cor do céu, montanha, clima) com os aspectos culturais de determinada sociedade. Trata-se de considerar o homem e os efeitos do seu trabalho como mediações indispensáveis à formação de paisagens. Ele se pergunta: "por que os povos agrícolas não se mudam para climas onde a natureza produz espontaneamente tudo e onde o trabaIho é mais favorável?...Hábito e amor à terra nativa, estes são as únicas razões que podem ser dadas" (HUMBOLDT, [1810] 1878, p.

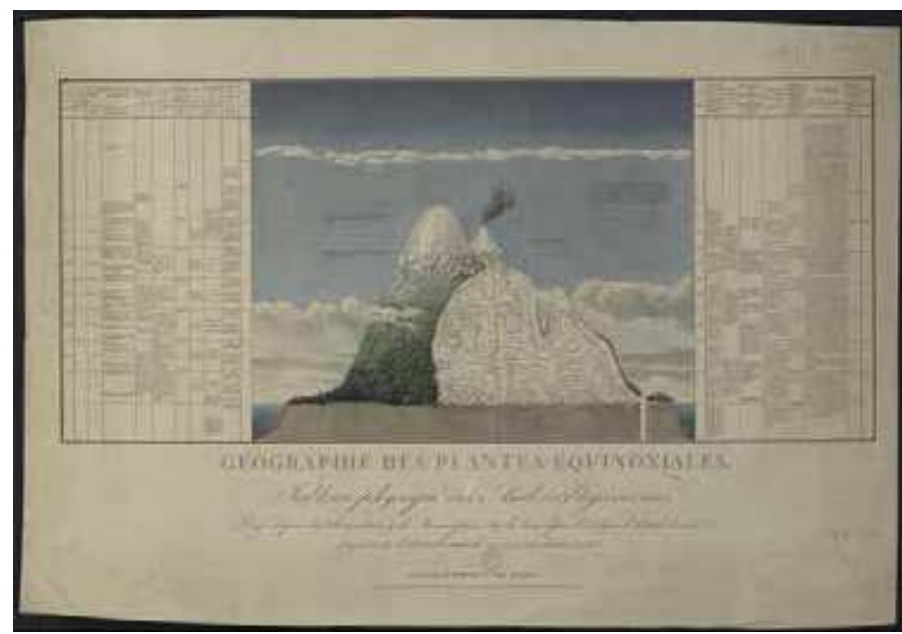

Figura 3 - HUMBOLDT, Alexander von; BONPLAND, Aimé. Tableau physique des Andes et pays voisin dresse $d$ après des observations et des mesures prises sur les lieux depuis le 10e degre de latitude boreale. Fonte: www.gallica. bnf.fr. Acesso em: 19 mai. 2018.
13). Em seu Sitios de las Cordilleras y Monumentos de los pueblos indígenas de América ([1810] 1878), Humboldt se preocupa em averiguar como a natureza possibilitou o aparecimento de novas modalidades de expressão cultural, como a linguagem, sem, contudo, se afastar de um núcleo. As línguas dos povos indígenas da América, embora difiram entre si das de origem germânica, apresentam certas similaridades no conjunto de sua organização (HUMBOLDT, [1810] 1878, p. 11). Porém, os elementos materiais da cultura - arquitetura, pintura, hieróglifo, equipamentos bélicos - seriam os instrumentos que revelariam antigos contatos entre os povos da América com as sociedades da Ásia e da Europa. Essa aproximação é notória na exposição da pirâmide (teocali) de Cholula, a qual, seguindo a exata direção do alinhamento do meridiano e do paralelo do lugar, assemelhava-se à implantação dos templos da Grécia (HUMBOLDT, [1810] 1878, p. 89).

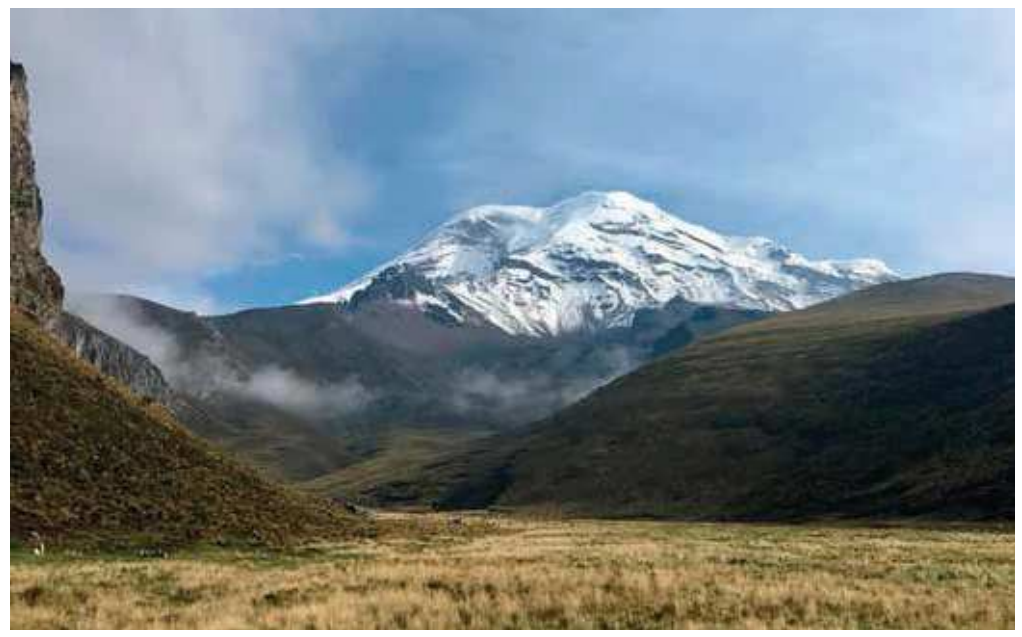

igura 4 - Chimborazo hoje. "O cume do Chimboraz tante da superfície da Terra desde o seu centro". Fonte: www.dw.com/de/ auf-den-spuren-alexander-von-humboldts/a-47407280. Accessed in: February 15 th, 2019 . 
O Sítio de las Cordilleras..., alinhado às reflexões postuladas em Quadros da Natureza, descreve paisagens à maneira dos relatos de viagem escritos por Goethe em seu périplo pela Itália. A mirada do espectador desvela a natureza com toda acurácia científica sem abandonar "o sopro benéfico da imaginação" (HUMBOLDT, [1810] 1878, p. 55).. Isso acontece quando Humboldt descreve o Paso de Quindiu:

Descobre-se uma vista pitoresca à entrada da montanha de Quindiu, nas cercanias de Ibaga e junto a um lugar que se chama Pie de la Cuesta. Aparece por cima de uma grande massa de rochas graníticas, o cone truncado de Tolima coberto de neve perpetua e recordando em sua forma o Catopaxi e o Cayambo; o pequeno arroio de Combeina, que mescla suas águas às do rio Cuello, serpenteia por um vale estreito, abrindo caminho através de um bosque de palmeiras, e além, ao fundo, se divide com parte da cidade de Ibaga o grande vale de Magdalena e a cadeia oriental dos Andes (HUMBOLDT, [1810] 1878 p. 55).

Percebe-se que Humboldt busca aplicar qualificativos da paisagem (pitoresco) a lugares exóticos conhecidos através de mapas ou pinturas de paisagens. Convém recordar que, no segundo volume de Cosmos há um capítulo devotado a explicar como o descobrimento da América reformulou o imaginário da Europa. Para tanto, os quadros do pintor flamengo Franz Post elucidam "formas individuais da natureza" (HUMBOLDT, 1852, p. 35) de regiões de difícil acesso, como o Brasil, pois até 1808 a Coroa portuguesa havia proibido expressamente a presença de naturalistas estrangeiros em seus domínios americanos ${ }^{4}$.

4 O rei de Portugal emitiu cartas régias a todas as vilas e cidades coloniais impedindo a entrada de Humboldt no Brasil, trantando-o como perigoso e dotado de ideias prejudiciais. Nas vereações da câmara da vila do Icó (capitania do Ceará) encontramos a seguinte ordem: "registro de uma ordem régia a todas as povoações com data de 20 de outubro de 1800 por intermedio do governador, com especial empenho a fim de ser preso um tal barão de Humboldt, subdito da Prussia, que á pretexto de estudar a geographia e topographia do centro da America, e debaixo do especioso pretexto de outras observaçōes científicas, procura surpreender e tentar, com ideias novas e capciosos principios, os animos dos povos seus fieis vassalos. Declara S. M. que estas viajens nos domínios de S. M. são summamente

\section{CONSIDERAÇÕES FINAIS: AFINIDADES ENTRE O POETA E O NATURALISTA}

De acordo com Cláudia Valladão de Mattos (2004, p. 153), o encontro de Goethe com Humboldt trouxe às proposições do naturalista a plena realização do pensamento do poeta sobre a ciência; de fato, Humboldt apropriou-se das ideias de Goethe em suas investigações. Eles compartilharam a crença de que a maravilha do homem pela beleza e vida da natureza poderiam inspirar a arte e a ciência. Ambos reconheceram que o aspecto holístico do cosmos não se reduz unicamente a modelos empíricos e mecanicistas, como o sistema botânico de Lineu que, segundo suas considerações, apresentava falhas conceituais, especulando a natureza segundo categorias abstratas e estanques em vez de divulgar a dinâmica e a transformação da vida natural (BELUZZO, 2000, p. 21). Por outro lado, Goethe se interessou em unificar o belo e a natureza numa mesma fonte. Para ele, por exemplo, precisava-se estudar a aparência das plantas e a partir dela pressupor a lei que controlava todas as manifestações individuais (Urphänomenou protofenômeno). Humboldt concorda na medida em que a natureza, em sua harmoniosa unidade, é bela e significativa, inspirando a sensibilidade do artista e a racionalidade do cientista na busca dos princípios que elucidam os fenômenos.

Sabe-se que Goethe enfatizou as características pelas quais todas as plantas mantiveram em comum, originárias de uma planta arquetípica e de um Urphänomen. Em A metamorfose das plantas, Goethe verificou que as folhas submersas de determinadas plantas semiaquáticas (a Ranunculus aquaticus) diferiam morfologicamente daquelas aéreas (GOETHE, 2009, p. 19). A morfologia, como uma transformação sucessiva viva, é a proposta de Goethe para o estudo do conjunto orgânico pela qual a exterioridade da forma complementa-se com os fenômenos ocultos ao sentido da visão. Em suas palavras: "nosso espírito está em harmo-

perigosas e prejudiciais aos interesses políticos de S. M., e o governador encarecendo sobre a opinião do seu monarcha, offerece um premio de $200 \$ \mathrm{rs}$. a quem trouxer preso este homem perigoso". Ver Revista do Instituto Histórico e Geográfico Brasileiro, tomo XXV, Rio de Janeiro, 1862, p. 75 
nia com o mais simples poder encontrado no fundo da natureza, e é capaz de representa-lo tão puramente como os objetos do mundo visível são formados claramente nos olhos" (apud WALLS 2009 , p. 229). Com efeito, a morfologia é um processo vital, assim como a formação das cores oriunda do íntimo contato entre luz (o protofenômeno) e o olho. No entanto, Humboldt tem uma ideia que é simultaneamente contrária e afim à teoria das cores goethena. Em Quadros da natureza ele esclarece: "todos os fenômenos nascem de uma fonte única, como as cores que se decompõem do raio luminoso; todos são resolvidos em uma força eterna e universalmente vital". Há, portanto, o reconhecimento do Urphänomen. Todavia, o Humboldt cientista não recusa por completo a teoria newtoniana de surgimento das cores a partir da fragmentação da luz branca. O ponto de confluência com Goethe, expresso nessa passagem, é justamente a força vita que rege todos os fenômenos, nomeada por Humboldt de Gênio Ródio. Sucintamente, o Gênio Ródio seria a existência de uma força oculta atuante na formação da natureza, designando uma unidade e uma progressão no mundo (SILVEIRA, 2015, p. 14).

A paisagem para Goethe e Humboldt aparece como uma porção vital da totalidade natural enquadrada pela sensibilidade do olhar treinado e transfigurada em arte (literatura e pintura). Como Vitte (2010) e Silveira (2010) refletiram, em Goethe a paisagem se transforma no ponto de reunião de formas tomadas pela intuição reveladora do todo. Essa noção será maximizada em Humboldt, cujos fundamentos da representação de paisagem não se restringiram à descrição de eventos; ao contrário, a paisagem possui uma fisionomia que lhe é própria derivada da conjunção harmoniosa de fatores humanos (terras agricultáveis, navegação, pastoreio, arquitetura) e naturais (nuvens, céu, vegetação, montanha) em um enquadramento, seja material (moldura) ou visual. Os desenhos de Goethe esboçados ao longo da viagem à Itália, os retratos do mundo "pintados" na narrativa epistolar do jovem Werther ${ }^{5}$ e as vistas dos monumentos dos povos indígenas da América ilustrados por Humboldt corroboram essa premissa.

5 Cf. carta de 26 de maio de 1774, pela qual o jovem Werther narra em vivas pinceladas a paisagem dos arredores do vilarejo de Wahlheim.

\section{REFERÊNCIAS BIBLIOGRÁfICAS}

ARRAES, Esdras. A paisagem e sua dimensão estética, Princípios: Revista de Filosofia Natal, v. 24, n. 45, set.-dez. 2017, p. 37-57. DOI: http://dx.doi.org/10.21680/1983-

ARRAES, Esdras Araujo. Além de nuvens e montes: a paisagem de Goethe antes da tália. In: ENCONTRO NACIONAL DO GT DE ESTÉTICA DA ANPOF, 9, 2018, Rio de Janeiro. Rio de Janeiro: PUC-Rio, 2018. p. 1-11.

ARNALDO, Javier et al. Johann Wolfgang von Goethe: paisajes. Madrid: Círculo de Bellas Artes; Weimar: KlassikStiftung Weimar, 2008.

BELUZZO, Ana Maria de Moraes. O Brasil dos viajantes.4 ed. Vol. II. Rio de Janeiro: Fundação Odebrecht, 2000.

BESSE, Jean-Marc. Ver a Terra: seis ensaios sobre a paisagem e a geografia. Tradução Vladimir Bartalini. São Paulo: Perspectiva, 2006.

BUTTIMER, Anne. Beyond humboldtian Science and Goethe's way of Science: challenges of Alexander von Humboldt's Geography. Erdkund. Kleve, v. 55, n. 2, p. 105-120, june, 2001

CAUQUELIN, Anne. A invenção da paisagem. Tradução Marcos Marcionilo. São Paulo: Martins Fontes, 2007

CORRESPONDENCES between Schiller and Goethe from 1794 to 1805. Vol. 1.Translated by George H. Calvert. New York and London: Wiley and Putnam, 1845. ECKERMANN, Johann Peter. Conversações com Goethe nos últimos anos de sua vida: 1823-1832. Tradução Mario Luiz Frungillo. São Paulo: Editora Unesp, 2016.

GALÉ, Pedro Fernandes. Em torno do olhar: a formação do método morfológico de Goethe. 2009. 106f. Dissertação (mestrado em Filosofia) - Faculdade de Filosofia, Letras e Ciências Humanas da Universidade de São Paulo, São Paulo, 2009.

GOETHE, Johann Wolfgang von. A metamorfose das plantas [1790]. Tradução de Maria Filomena Molder. Lisboa: Imprensa Nacional - Casa da Moeda, 1993.

GOETHE, J. W. Sobre a arquitetura alemã [1772]. In: Escritos sobre a Arte. Tradução de Marco Aurélio Werle. São Paulo: Humanitas; Imprensa Oficial, 2005.p. 39-49.

GOETHE, J. W. Resenha sobre as belas artes de Sulzer [1772]. In: Escritos sobre a Arte. Tradução de Marco Aurélio Werle. São Paulo: Humanitas; Imprensa Oficial, 2005. p. $51-57$.

GOETHE, Johann Wolfgang von. Os sofrimentos do jovem Werther [1774]. Tradução Erlon José Paschoal. São Paulo: Estação Liberdade, 2009.

GOETHE, J. W. O jogo das nuvens. Tradução João Barrento. Lisboa: Assírio \& Alvim

GOETHE, J. W. Doutrina das cores[1810]. 4 ed. São Paulo: Nova Alexandria, 2013. GOETHE, Johann Wolfgang von. De minha vida: poesia e verdade. Trad. Maurício de Mendonça Cardozo. São Paulo: Editora Unesp, 2017a.

GOETHE, Johann Wolfgang von. Viagem à Itália. Tradução Wilma Patrícia Maas. São Paulo: Editora Unesp, 2017b.

GOETHE, Johann Wolfgang. Novela ou a história de uma caçada. Sintra: Colares Editora, s.d.

HACKERT, Jacob Philipp; GOETHE, Johann Wolfgang von. Lettere sulla pintura di paesaggio. A cura di Paolo Chiarini. Roma: Artemide, 2002. 
HUMBOLDT, Alexander von. Cosmos, o ensayo de una descripción física del mundo. HUMBOLDT, Alexander von. Cuadros de la naturaleza [1808]. Madrid: Imprenta y HUMBOLDT, Alexander von.
Libreria de Gaspar, 1876.

HUMBOLDT, Alexander von. Sítios de las cordilleras y monumentos de los pueblos indígenas de América [1810]. Traducción Bernardo Giner. Madrid: Imprenta y Libreria de Gaspar Editores, 1878.

HUMBOLDT, Alexander von. Essay on the Geography of plants [1807]. The Chicago University Press, 2009.

LUKÁCS, Georg. Goethe y su época. Barcelona: Ediciones Grijalbo, 1968.

MEDINA, Juan Antonio Ortega y. El ensayopolitico de Humboldt. In: ZEA, Leopoldo; MAGALLÓN, Mario (comp.). La huella de Humboldt. México: Fondo de Cultura Económica, 2000. p. 99-14

MATTOS, Cláudia Valadão. A pintura de paisagem entre a arte e a ciência: Goethe, Hackert, Humboldt. Terceira Margem: Revista do Programa de Pós-Graduação em Ciência da Literatura, Rio de Janeiro, n. 10, p. 152-169, 2004.

MILANI, Raffaele. Estética y crítica del paisaje. In: NOGUÉ, Joan (ed.). El paisaje em la cultura contemporánea. Madrid: Biblioteca Nueva, 2008. p. 45-66.

MILLER, Gordon L. Introduction. In: GOETHE, Johann Wolfgang. The metamorphosis of plants. Cambridge: MIT Press, 2009. p. 16-32.

MOLDER, Maria Filomena. O pensamento morfológico de Goethe. Lisboa: Imprensa Nacional - Casa da Moeda, 1995.

REVISTA do Instituto Histórico e Geográfico Brasileiro. Rio de Janeiro: tomo XXV,

\section{2.}

RITTER, Joachim. Paisagem: sobre a função do estético na sociedade moderna. In: SERRÃO, Adriana Veríssimo (coord.). Filosofia da paisagem. Uma antologia. 2 ed. Lisboa: Centro de Filosofia da Universidade de Lisboa, 2013.

ROUSSEAU, Jean-Jacques. Os devaneios de um caminhante solitário. Tradução Julia da Rosa Simões. Porto Alegre: L\&PM, 2017.

SILVEIRA, Roberison Wittgenstein Dias da. O Gênio Ródio de Alexander von

Humboldt. Sociedade e Natureza. Uberlândia, v. 27, n. 1, p. 7-20, jan./abr., 2015.

VITTE, Antonio Carlos; SILVEIRA, Roberison Wittgeistein Dias da Silveira. Natureza em Alexander von Humboldt: entre a ontologia e o empirismo. Mercartor, v. 9, n. 20, p.

WALLS, Laura Dassaw. The passage to cosmos: Alexander von Humboldt and the shaping of America. Chicago: The University of Chicago Press, 2009.

WERLE, Marco Aurélio. Winckelmann, Lessing e Herder: estética do efeito? Trans/ Form/Ação. São Paulo, v. 23, n. 1, p. 19-50, 2000.

WERLE, Marco Aurélio. Natureza e sociedade no Werther de Goethe. Artefilosofia. Ouro Preto, n. 22, p. 38-49, jul, 2017

\section{Esdras Arraes}

Universidade de São Paulo, Faculdade de de Filosofia, Letras e Ciências Humanas (FFLCH-USP). Departamento de Filosofia.

Avenida Prof. Luciano Gualberto, 315. Sala 1007. Cidade Universitária. CEP: 05508-010. São Paulo - SP.

CV: http://lattes.cnpq.br/0462029779554770

Orcid: https://orcid.org/0000-0003-0374-7401

Email: esdras_arraes@yahoo.com.brou esdrasarraes@gmail.com Pesquisador de pós-doutorado com bolsa da Fundação de Amparo à Pesquisa do Estado de São Paulo - FAPESP (processo 2017/12296-2).

\section{Agradecimentos}

Sou grato ao meu supervisor, o Professor Titular Marco Aurélio Werle, pela prontidão de indicar a trajetoria bibliográfica de Goethe e de outros filósofos de sua época. Ao prof. Dr. Euler Sandeville Jr. da FAU-USP pela leitura atenciosa e apreciação do texto. Ainda sou agradecido à Fundação de Amparo à Pesquisa do Estado de São Paulo (FAPESP) pela concessão da bolsa de pós-doutorado (processo número 2017/12296-2) por meio da qual existe a possibilidade de divulgar ideias filosóficas sobre a paisagem pintada em vivo colorido nas obras de Goethe e Alexander von Humboldt. Muito obrigado

\section{Nota do editor}

Revisão do texto: Autor

Submetido em. 25/05/2018

Aprovado em: 29/10/2018 